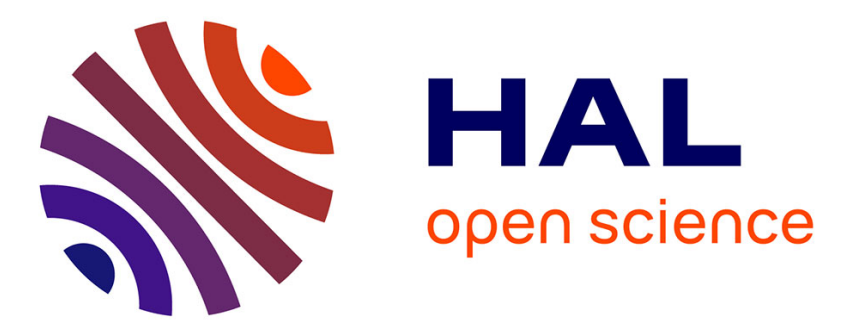

\title{
Transitioning to a new topic in American English conversation: A multi-level and mixed-methods account Marine Riou
}

\section{To cite this version:}

Marine Riou. Transitioning to a new topic in American English conversation: A multi-level and mixedmethods account. Journal of Pragmatics, 2017, 117, pp.88 - 105. 10.1016/j.pragma.2017.06.015 . hal-01915836

\author{
HAL Id: hal-01915836 \\ https://hal.science/hal-01915836
}

Submitted on 20 Nov 2018

HAL is a multi-disciplinary open access archive for the deposit and dissemination of scientific research documents, whether they are published or not. The documents may come from teaching and research institutions in France or abroad, or from public or private research centers.
L'archive ouverte pluridisciplinaire HAL, est destinée au dépôt et à la diffusion de documents scientifiques de niveau recherche, publiés ou non, émanant des établissements d'enseignement et de recherche français ou étrangers, des laboratoires publics ou privés. 
Journal of Pragmatics 117 (2017) 88-105

DOI 10.1016/j.pragma.2017.06.015

\title{
Transitioning to a new topic in American English conversation: a multi-level and mixed-methods account
}

\author{
Marine Riou ${ }^{\mathrm{a}, \mathrm{b}}$ \\ a Prismes - Langues, Textes, Arts et Cultures du Monde Anglophone, Université \\ Sorbonne Nouvelle, 4 rue des Irlandais, 75005 Paris, France \\ ${ }^{b}$ Laboratoire de Linguistique Formelle, Université Paris Diderot, 5 rue Thomas Mann, \\ 75013 Paris, France
}

\begin{abstract}
In talk-in-interaction, transitioning to a new (discourse) topic is an interactional action which involves the mobilization of a number of linguistic cues. This paper presents a holistic analysis of the design of topic transition in spontaneous conversation by combining qualitative analysis, instrumental prosody, and statistical modeling. To investigate the grammatical patterns that participants routinely mobilize for their turns initiating topic transitions, three types of cues are taken into account: pitch register, discourse markers, and questions. Each type of cue is analyzed for its individual contribution to topic transition design, as well as for the way it can combine with other cues. Analyzing different types of cues - verbal and prosodic - creates a composite picture of the various ways in which the topic trajectory of a conversation shapes its grammar - including its prosody.
\end{abstract}

\section{Keywords}

English, conversation, topic, prosody, discourse markers, questions 


\section{Introduction}

Speakers and analysts usually share the intuition that, in the course of casual interaction, a number of topics are discussed in turn by conversational participants. If different topics are raised, then there is a moment of junction when participants switch from one topic to the next. Following previous work in the Conversation Analysis framework (Button and Casey, 1984, 1985; Holt and Drew, 2005; Jefferson, 1984), I refer to this pivot moment of topic structure as topic transition. It constitutes a sequential position (a topic-sequence boundary) and an interactional action (switching topics). An occurrence of a topic transition, indicated by an arrow, can be seen in the following example. Alina (ALN) was talking about her husband's colleagues, who work for a production company. After she detailed the professional background of one of them, she initiates a topic transition (I.7) about an evening she spent at this colleague's new house (a list of transcription conventions can be found in Appendix A).

(1) Their house (SBC006, 1462-1473)

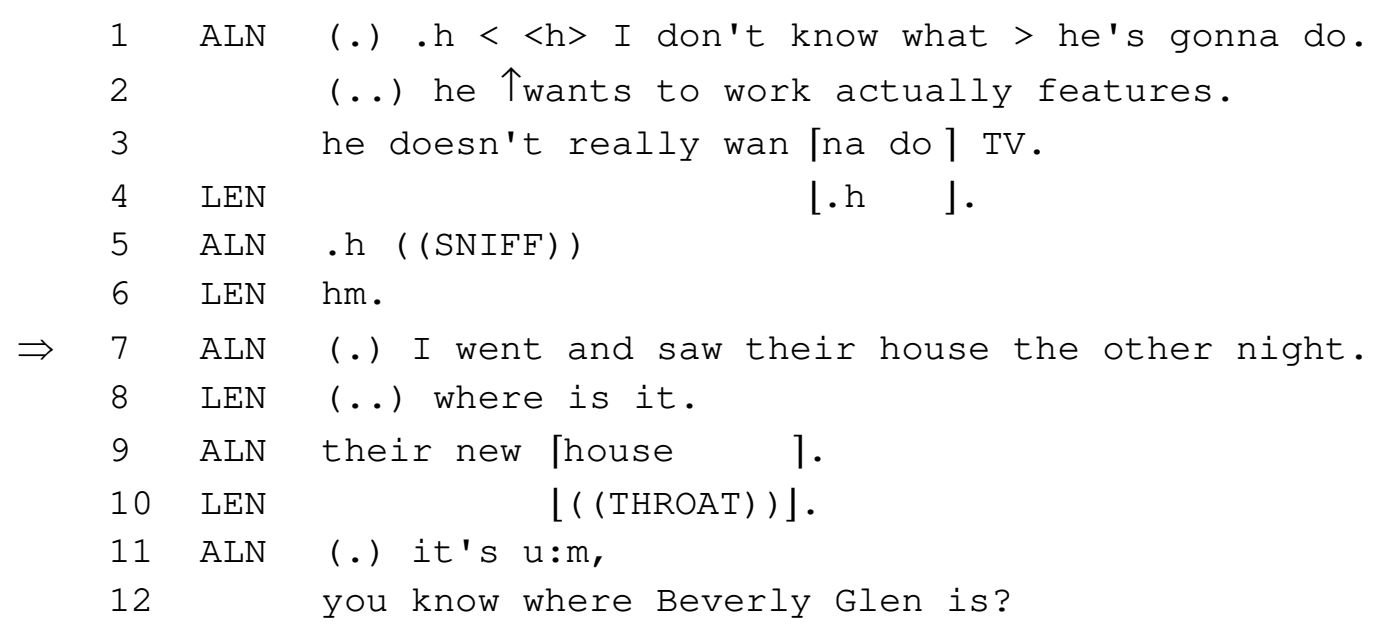

ALN's transition (I.7) is not grammatically designed in a way that proclaims its status of transition, but its sequential placement indicates it clearly: the preceding topic has 
manifestly come to a halt and a lull in the conversation threatens to set in (I.4-6). This environment is typical of new topic introductions (Maynard, 1980).

By contrast with the extract presented in (1), many topic transitions in talk-ininteraction are delivered with a format involving recurring grammatical cues. As it investigates prosodic cues on a par with verbal cues, this study holds the view that prosody is a part of grammar (see Couper-Kuhlen and Selting, 1996 inter alia). In this paper, I focus on three types of cues mobilized by participants to initiate a topic transition: questions (did you ever get into Tesla?), discourse markers (so / called Laura today), and expanded register span ( $<<\exp >$ think about the kids $>$ ). Previous research has studied each of these cues individually to assess its contribution to the structure of interaction (see section 2.2). However, earlier studies have rarely combined the analysis of several types of cues in a systematic way.

This paper adds to a previous publication about the same dataset (Riou, 2017), which focused solely on the prosody of topic transition, investigating the role played by variations of pitch register. Two dimensions of pitch register were investigated in Riou (2017): register level (i.e., high vs. low) and register span (i.e., expanded vs. compressed). The present study complements this account by integrating the analysis of verbal cues (discourse markers and questions) to that of prosodic cues. It is characterized by hybridism in two ways. Firstly, it analyses the contribution of verbal and prosodic cues separately, as well as in combination. Secondly, this study lies at the interface of Conversation Analysis, Interactional Linguistics, Pragmatics, and Corpus Linguistics, borrowing from their respective methodologies and previous findings. The methods used here are mixed, as they associate qualitative analysis to systematic coding and statistical modeling. As has been argued by Robinson (2007), Stivers (2015), and Kendrick (2017), systematic coding and statistics can make precious additions to the methodological arsenal at the interactionist's disposal. I used logistic regression, a confirmatory statistical technique, to determine whether the presence of a certain format can predict whether a turn initiates a topic transition. 
Based on this statistical modeling, I argue that conversational participants mobilize a distinct set of verbal and prosodic cues for their topic transitions: questions, discourse markers, and pitch register variations. What is more, results suggest that topic transition routinely mobilizes these different cues in combination, i.e., topic transitions are typically signaled by more than one cue.

Section 2 provides some theoretical background on topic in talk-in-interaction. Section 3 presents the data and methods. Section 4 focuses on the specific role that register span, discourse markers, and questions play in topic transition. Section 5 considers the three types of cues together and analyzes their combined contribution by means of statistical modeling and qualitative analyses.

\section{Background}

\subsection{Topic in interaction}

Topic should be kept analytically distinct from two phenomena: sentence-topic (Stopic) and sequence. In the perspective of information structure (Lambrecht, 1994), S-topic is what a sentence is about (vs. the "focus"). Within Functional Grammar (Halliday and Matthiessen, 2004), S-topic (the "theme") is the first element of a sentence (vs. the "rheme"). From a conversation analytic perspective, it has been argued that the notion of topic and sequence should not be conflated (Couper-Kuhlen, 2004), even though some sequences can be specifically organized around the management of topic structure, such as topic-proffering sequences (Schegloff, 2007:169-180).

This paper builds on a definition of topic which was compiled in a previous publication (Riou, 2015) from the existing literature in Conversation Analysis, Interactional Linguistics, and Pragmatics. Three defining features of topic were highlighted: (1) topic is the center of shared attention, (2) it is participant- and interaction-specific, and (3) it is co-constructed by participants. Firstly, the notion of 
center of shared attention can be connected to Gundel et al.'s (1993) cognitive focus and Chafe's (1994) analogy between focal and peripheral vision: when participants are engaged in talk about a certain topic, this topic is in their focal zone of attention. Secondly, seeing topic as participant- and interaction-specific acknowledges that topics are not autonomous discourse objects. Rather, topics are created and negotiated in real time by participants, and so, are unique to a specific interaction (Mondada, 2001, 2003). Finally, the last feature of this definition of topic considers that it is a joint product negotiated by participants (Geluykens, 1993; Mondada, 2001). Defining topic as a co-construction is one response to the difficulty of treating cases of aborted topics. In theory, any turn can be interpreted as a topic transition, as any turn could have potentially led to a subsequent development by focusing on its individual content. When one participant initiates a topic transition, the other participant(s) can then respond to it in different ways in the next turn(s). Unless the co-participant(s) allows the new topic to be developed, e.g., by producing a turn about the new topic or by letting the initiating participant produce a turn about it, it can be very problematic to consider that a new topic arose. Using participant orientation can offer more robust guidelines by focusing on interactional evidence that a new path of topic development was suggested, and then taken up, ignored, or declined. For a more thorough review of the notion of topic in discourse and interaction, the reader is referred to Berthoud (1996), Goutsos (1997), Grobet (2002), and Zellers (2013).

A lot of work has been devoted to the notion of topic, but many studies investigated only one type of topic transition or topic sequence. For example, Jefferson (1984) focused on stepwise topic transitions, i.e. when participants gradually move away from one topic to another. Another example is Zellers (2013), who analyzed a subset of topic transitions implemented over a contrastive structure. Other studies took a semasiological approach and inquired into the role that a specific linguistic form can play in topic structure, such as figurative expressions in the analysis presented in Holt and Drew (2005), sequence-opening so in Bolden (2008), higher-pitched onset 
syllable (Nakajima and Allen, 1993), or the role of questions in topic proffers (CouperKuhlen, 2012; Schegloff, 2007). Such an ample body of research contributes to a better understanding of topic management, but it lacks a systematic analysis of how various types of cues co-exist and all participate in the implementation of the same interactional action.

\subsection{Signaling a topic transition}

A topic transition does not necessarily imply switching to an entirely new topic completely unaddressed before. Topic transition is taken to be a switch from the current topic to a different one, i.e. a transition to a subject other than the one which was being discussed immediately prior. This means that topic transition can also involve returning to an older topic, or moving on to a different aspect of the topic being discussed. Participants are constantly changing the topic of conversation at hand, with varying levels of fluidity or abruptness, which is captured by the traditional distinction made between stepwise transition (also called "topic shading") and disjunctive transition (Holt and Drew, 2005; Jefferson, 1984; Maynard, 1980). However, when participants transition from one topic to another, the structure of interaction requires them to fit their turn to ongoing talk. This may be done by signaling how the new topic is connected to prior talk, or rather by signaling how it is disconnected from prior talk:

"Because the fundamental ordering principle of conversation is adjacency or contiguity (Sacks 1992: 554), if a turn is 'next positioned' it will by default be understood to relate to the immediately preceding turn. The consequence of this is, as Heritage puts it, "If a speaker wishes some contribution to be heard as unrelated to an immediately prior utterance, the speaker must do something to lift the assumption" (1984:261). So continuing what went before is the unmarked option, and beginning something new the marked option for next turns at points of possible sequence closure."(Couper-Kuhlen, 2004:336)

\section{Page 6 of 41}


Transitioning to a new topic can be implemented in different ways, and the main goal of this paper is to identify and analyze some of the structures that can be mobilized by participants. The aim of this function-to-form approach is to circumscribe a repertoire of strategies. Tannen (1984) used the term "pragmatic synonymy" to refer to this possibility of "different linguistic devices to achieve similar ends". Participants may mobilize a large variety of structures and modalities to implement one particular interactional action. In context, a potentially infinite number of forms could be mobilized to implement one specific action. Mondada (2001) used the term "bricolage" to characterize the way participants can opportunistically mobilize whatever works in a given context. The goal here is not to identify all such structures, as it would be virtually impossible to impose a limit to the number of possibilities harnessed by participants in a given context. Consequently, my focus here is rather to identify forms that are routinely mobilized by participants - which does not eliminate the possibility of other forms being used in specific contexts, or by speakers with different backgrounds.

A variety of cues to topic transition have been suggested in the literature. However, existing studies have tended to focus on one cue at a time. Concerning prosody, it has been suggested that new topics in spontaneous speech are signaled with high onsets (Nakajima and Allen, 1993; Yule, 1980), high register level (Yule, 1980), and expanded register span in the following turn for transitions using a contrastive expression as pivot (Zellers, 2013).

Discourse markers (DMs), such as well, anyway, so or you know, have regularly been associated to diverse cohesive and textual functions (Fraser, 1999; Jucker and Ziv, 1998; Schiffrin, 1987; Schourup, 1999), and topic management is one of them (Horne et al., 2001). Discourse markers tend to appear at the left-periphery of the TCU - they are sometimes called turn-initial objects (Heritage, 2013) or turn-initial elements (Kim and Kuroshima, 2013) in the conversation-analytical framework. CA studies of turn preface have tended to focus on individual DMs, such as change-of- 
state token oh (Heritage, 1984), sequence-opening so (Bolden, 2008), and retroactive indexer of relevance wel/ (Kim, 2013). Initial position is a locus for discourse organization (Degand, 2014), and this is the reason why DMs are analyzed as a category rather than individually in the present study. DMs are not defined here by their sequential position, but by their discourse-pragmatic properties. They are taken to correspond to a functional category of items with discourse-organizational functions whose scope is the utterance and which work at the communicative, dialogic, non-propositional domain (Diewald, 2013).

Questions represent another key strategy used by participants to engage others in a new topic, as the mechanism of the question-answer sequence can be mobilized for transition, either proffering or inviting a new topic with a question (Schegloff and Sacks 1973; Schegloff 2007:170; Mondada 2001). The participant designing a transition as a question contributes the first pair part of an adjacency pair, which makes it relevant next for the co-participant to produce the second pair part, i.e., an answer. Through conditional relevance, the recipient is likely to produce on-topic talk, as an answer will tend to be about the topic introduced. The difficulty of defining questions stems from the absence of formal criteria valid cross-linguistically as well as across all question types (Hayano, 2013). Following Stivers and Rossano (2012), "question" is defined here neither as a form or a function, but rather as a "collection of features". Stivers and Rossano (2010) identified four response-mobilizing features: interrogative lexico-morphosyntax, interrogative prosody, recipient-focused epistemicity, and speaker gaze. Their analysis draws on the traditional view that question design tends to involve interrogative grammatical structure, but it expands on this conception by adding two features to account for question use and interpretation in interaction - gaze and co-construction of knowledge.

The three types of cues analyzed here work across different linguistic dimensions. Discourse markers are a turn-initial practice which can project how the turn is going to fit with prior talk. Expanded register span is a prosodic contextualization cue 
signaling disjunction through the mobilization of a marked prosody (see Sicoli et al., 2015). Questions pertain to sequential structure, as they make the topic transition coincide with the first pair part of a question-answer sequence. The qualitative analysis of the corpus suggests that these three types of cues are pervasive across participants, conversations, and different types of topics and topic transitions. This study aims to investigate their collective contribution to the linguistic design of topic transitions.

\section{Corpus and methods}

\subsection{Corpus}

All analyses were conducted using a small-scale corpus of spontaneous dyadic conversations between friends or relatives. The data used for this study corresponds to six 15-min conversations ${ }^{1}$ extracted from the Santa Barbara Corpus of Spoken American English (Du Bois et al., 2000-2005), amounting to a total recording time of 90 min and 12 different speakers. This audio corpus of face-to-face interaction does not contain video recordings, which means that an important part of talk-ininteraction (Kendon, 2004; Streeck et al., 2011) was not available for analysis. The limited size of the corpus is due to the fact that this project integrates prosodic analysis of pitch, which requires time-consuming annotation. This study focuses on 175 tokens of topic transitions and 275 tokens of topic continuity, as detailed in section 3.3 .

\footnotetext{
${ }^{1}$ The conversations analyzed in this paper are: SBC005 ("A Book about Death"), SBC006 ("Cuz"), SBC007 ("A Tree's Life"), SBC017 ("Wonderful Abstract Notions"), SBC043 ("Try a Couple Spoonfuls"), and SBC047 ("On the Lot") from the Santa Barbara Corpus (Du Bois et al., 2000-2005).
} 


\subsection{Minimal unit segmentation}

Rather than using the available segmentation of the Santa Barbara Corpus into intonation units, I opted for the turn-constructional unit (TCU) as the minimal unit for this study. Transitioning to a new topic is a conversational move, and as such, can be implemented over the course of one interactiona/ unit. The TCU is such a unit, as it corresponds to a potentially complete turn-at-talk (Clayman, 2013; Ford et al., 1996; Sacks et al., 1974). Zellers (2011) argued that there is little reason to think that topic structure is inscribed in the phonology:

"It seems relatively clear that this [topical] structure is not a part of the phonology of a language per se; that is, we would not expect to find topicstructure variation encoded as part of an intonational grammar. Instead, it is part of the discourse structure." (Zellers, 2011:81-82)

The corpus was segmented into TCUs following the guidelines proposed in Ford et al. (2002), Local and Walker (2004), and Selting (2000) for a total amount of 2606 TCUs.

\subsection{Identifying topic transitions}

Each TCU was then analyzed individually, based on the definition of topic discussed in section 2. I used a very basic typology distinguishing only between Topic Transition and Topic Continuity. The reason for this choice was to allow for a systematic coding which could be carried out easily and which would rest on as few pre-conceptions of topic transition as possible. This is in line with Grosz and Sidner (1986) who argued that, as the number of functions which a discourse segment could have is virtually infinite, it is more reasonable to envisage more general discourse relationships. Through this process, a total of 212 Transitions and 2394 Continuities were identified. Concerns of circularity, subjectivity, and reproducibility were addressed by means of an inter-rater agreement. A second coder who was not informed of which specific cues were under scrutiny conducted an independent 
identification of topic transition on 33\% of the corpus ( 2 conversations out of 6 ). This procedure yielded a substantial agreement (Cohen's kappa, $\kappa=0.73$ ), which can be considered a form of verification. The use of inter-rater agreement to verify topic identification was presented in more details in Riou (2015). Another example of the use of this methodological tool on interactional data can be found in Kendrick and Torreira's (2015) analysis of timing and preferredness.

The present study did not take into account all the 2606 TCUs of the corpus, but a subset of 450 TCUs (175 Transitions, 275 Continuities). The reason for this is that some TCUs of the corpus were not fit for an instrumental analysis of prosody. This subset of 450 TCUs is the same as the one analyzed in Riou (2017), and the reader is referred to this previous publication for more details on the acoustic criteria used for inclusion.

\subsection{Systematic coding}

Using a systematic coding scheme, I analyzed each TCU for a number of interactional, syntactic, pragmatic, and prosodic parameters, such as the use of an initial discourse marker or a question, in the perspective of multifactorial usagefeature analysis (Glynn, 2014): usage features are uncovered through the systematic manual coding of large collections of data. Each usage feature can then be treated as a variable and multivariate statistics can be conducted. Multifactorial usage-feature analysis can be thought of as a way of conducting situated qualitative analysis on a large scale and with features operationalized so that statistical testing can be performed.

Despite recent contributions to the debate such as Stivers (2015), it should be noted that systematic coding as a research practice still stands at the fringe of Conversation Analysis and Interactional Linguistics. Conversation Analysis has a long history of being wary of quantification (Schegloff, 1993), as the close analysis of the uniqueness of specific cases is at the heart of its methodology: 
"the focus on quantification tends to lead the analyst away from considering, closely and on a case-by-case basis, how the participants themselves are orienting to one another's actions." (Hutchby and Wooffitt, 1998:119)

However, recent studies have incorporated more quantitative-oriented tools to ask questions of interest to Conversation Analysis (Kendrick and Torreira, 2015; Kurtic et al., 2009; Stivers et al., 2009; Stivers and Enfield, 2010; Zellers and Ogden, 2014). For the present study, classic conversation-analytic methodology (Clift, 2016; Sidnell and Stivers, 2013) preceded the implementation of a coding system and quantification, as recommended by Robinson (2007). Indeed, only a careful qualitative analysis can provide the coding categories adequate to a specific research question and data. The systematic coding then made it possible to work through a sizeable body of data, draw parallels, retrieve items with similar or dissimilar features promptly and thoroughly, as well as conduct multivariate statistics. And finally, only a qualitative mindset can give meaning to the results obtained through quantification.

\subsection{Prosodic analysis}

To analyze register span across speakers, I used a measure of dispersion to define individual thresholds above which it was reasonable to assume that a speaker was mobilizing an expanded span - with respect to their own voice range. This method is very similar to Sicoli et al.'s (2015), who analyzed initial pitch in questions to determine whether onset height is predictive of the action it carries out. Rather than assuming that an absolute measure such as "2 octaves" corresponds to a "standard" or "expanded" span, I measured the register span of each TCU uttered by each speaker by means of the speech analysis software Praat (Boersma and Weenink, 2012). Based on the individual profiles drawn for each participant, I used a statistical measure of dispersion to determine the threshold defining span values as "expanded". I opted for the third quartile (QB) as a cut-off point. As the values above Q3 correspond to the speaker's top $25 \%$ values, this threshold ensures that any value 
above QB is likely to be qualitatively "expanded", and as such, can be considered a rather marked value (see Riou, 2017 for more details on the operationalization of register span as a variable).

\subsection{Statistical analysis}

Logistic regression is "a confirmatory technique for statistically modeling the effect of one or several predictors on a binary response variable" (Speelman, 2014: 488) and a subtype of generalized linear models. The response variable, or outcome, corresponds to the phenomenon analyzed. In the present case, the response variable is "topic structure" and has two possible values: Transition and Continuity. The logistic regressions presented here model the effect that various predictor variables have on topic structure, i.e. the effect that the variables "question", "discourse marker", and "expanded span" can have on the possibility that a TCU is a Transition or Continuity. Statistical analyses were conducted with the software $R$ ( $R$ Development Core Team, 2013) with the following three functions: glm(), $\operatorname{lrm}()(\mathrm{rms}$ package, Harrell, 2014), and glmer () (lme4 package, Bates et al., 2014).

\section{Individual cues to topic transition}

\subsection{Expanded pitch range}

The extract presented in (2) is a typical example in which register variations cue topic transition. JIM and MIC have been discussing technological advances, and agreed that scientists work so fast that they build on improving technologies already extremely recent and advanced - which gives the impression that one can just "conjure something up" (I.6):

\section{(2) Superconductors (SBC017, 217-237)}

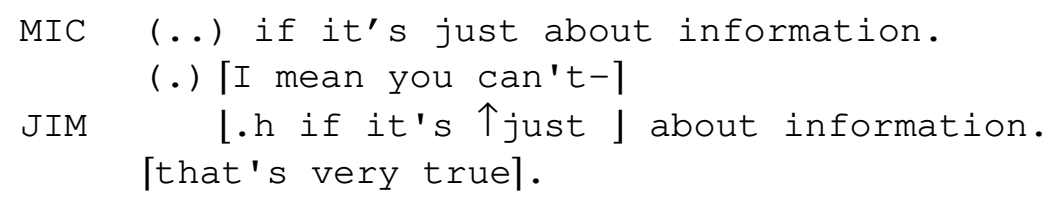




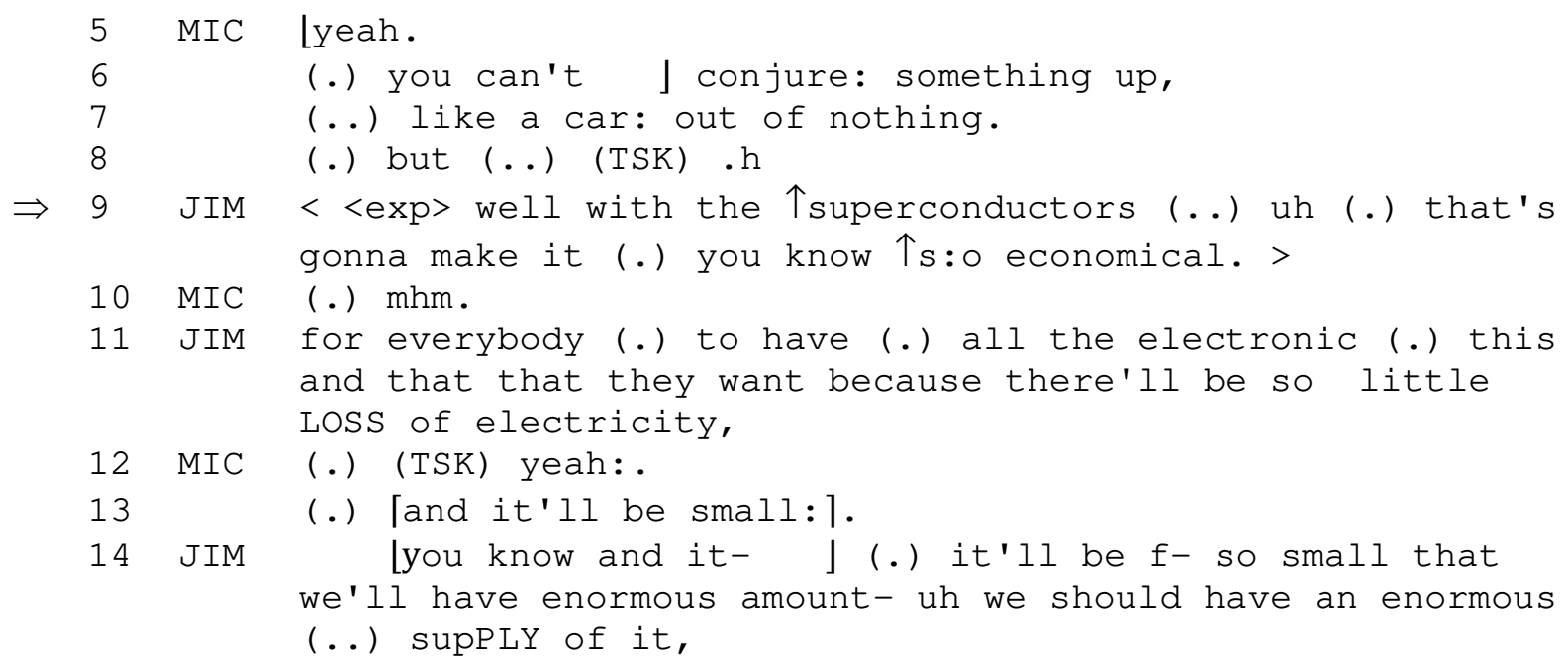

L.9, JIM initiates a topic transition about "superconductors". His transition starts with a high onset (first syllable of "superconductors") and is delivered with an expanded register span, stretching over the entire TCU. JIM's subsequent turn (I.11) is an increment to the transition, but as the transition is already effective and ratified by MIC's backchannel (“mhm" I.10), JIM reverts back to a less marked register span.

\subsection{TCU-initial discourse markers}

Even though DM-prefaces are pervasive throughout talk-in-interaction, they are a distinctive feature of topic transitions in particular. Extract (3) is a typical example of a topic transition prefaced with a DM, where more than one DM is mobilized. SCO is sitting at his computer and looking for an internet provider for KAR's father:

\section{(3) Spider plant (SBC034, 368-382)}

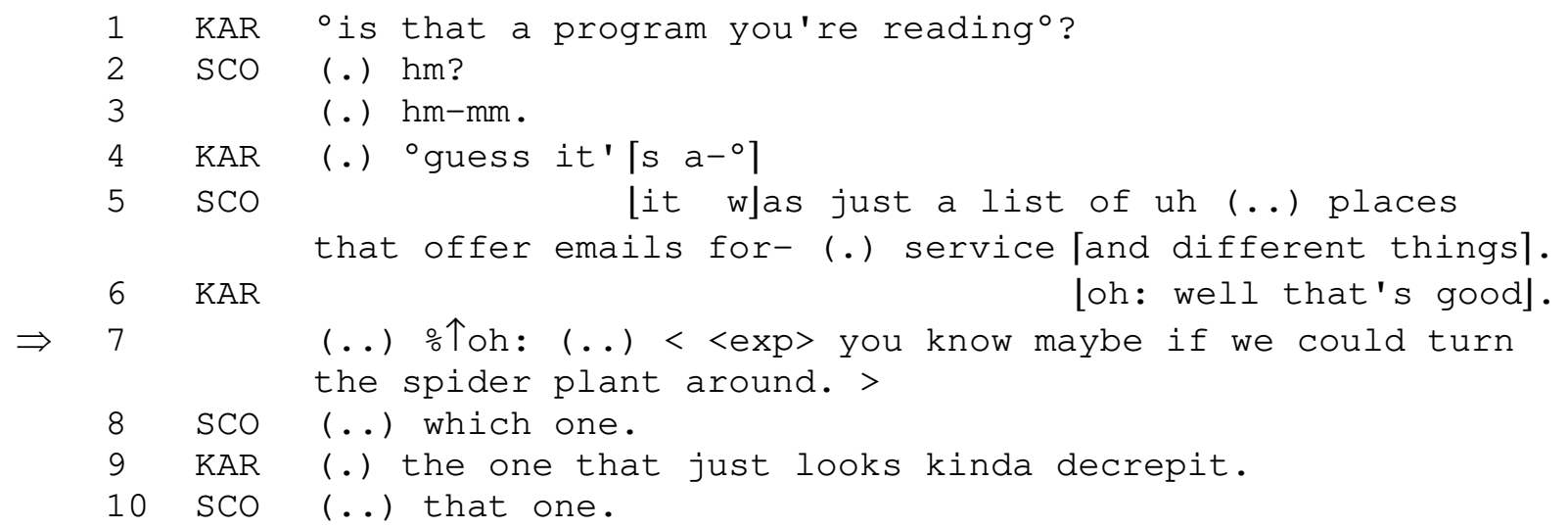


11 KAR yeah.

12 SCO (..) maybe we could- I think it (..) would probably do better if it got its babies trimmed off.

KAR makes a topic transition (I.7) about the couple's plants. Her transition is prefaced with two DMs, oh and you know. These two DMs can be thought of in terms of division of labor. For Bolden (2006), oh can function as "a preface to utterances that launch new action trajectories". Oh has been analyzed in the literature as a change-of-state token (Heritage, 1984), indicating that the participant has experienced a change of knowledge, information, orientation, or awareness. In the case of a topic transition, prefacing one's turn with oh can be taken to index the turn as resulting from such a change of state. In (3), KAR's turn transition (I.7) is motivated by a change in her awareness and orientation: she notices the spider plants, which emerge as the new cognitive focus in her attentional state. In their experiments on spontaneous speech comprehension, Fox Tree and Schrock (1999) found that oh helps listeners integrate disjunctions in discourse, as evidenced by faster processing time. Following oh, the DM you know functions at a different plane of talk. Often interpreted as an intersubjective marker of shared knowledge, Jucker and Smith (1998:196) interpret you know as "a strategic device used by the speaker to involve the addressee in the joint construction of a representation". In (3), KAR's you know involves SCO in the discussion of the plants even before she states the new topic, and also invites him to draw the correct inferences about them - namely, that something needs to be done, this being the reason why KAR is raising the topic. Taken together, this association of oh and you know at the beginning of KAR's transition allows her to cue a disjunction and involve her addressee in the new topic-sequence she opens.

Through their discourse segmentation properties, DMs as a category are harnessed to signal topic transition in interaction. A DM-preface is typical of Transitions, as they signal various ways in which the turn is about to fit to the topic architecture being developed. For example, a participant can signal with anyway that 
the upcoming turn is about to revive a previously interrupted topic (Park, 2010; Sacks, 1992), or with so that it is occasioned by something other than the immediately preceding talk (Bolden, 2009)

\subsection{Questions}

The proportion of topic transitions taking the form of a question goes far beyond their proportion in the rest of the corpus: 25\% (52) of the 212 Transitions took the form of a question, while questions represented only 8\% (191) of the 2394 other TCUs (Continuity). There is some evidence that participants consider topic questions to initiate a specific action through their orientation to the topic component of said questions. Request for information is one of the most common social actions carried out by questions (Stivers, 2010), e.g., by contrast with requests for confirmation and repair initiations (Stivers and Enfield, 2010). Requests for information can be harnessed by participants to initiate topic transition. There is evidence that participants orient not only to such a question as a request for information, but also as soliciting a fair amount of on-topic talk. Minimal answers only providing the piece of information requested and not expanding on the topic are not treated as optimal by the questioner, who may pursue more extended on-topic talk. Extract (4) is one such case. RIC has been talking about his recent break-up due to his infidelity (I.1-2) and explains that he misses his ex-partner (I.9), especially when he comes home after a long day at work (I.10-13). His cousin FRE then initiates a topic transition with a question about RIC's new work schedule ("are you working twelve hours?" I.15):

\section{(4) Nine to nine (SBC047, 505-554)}

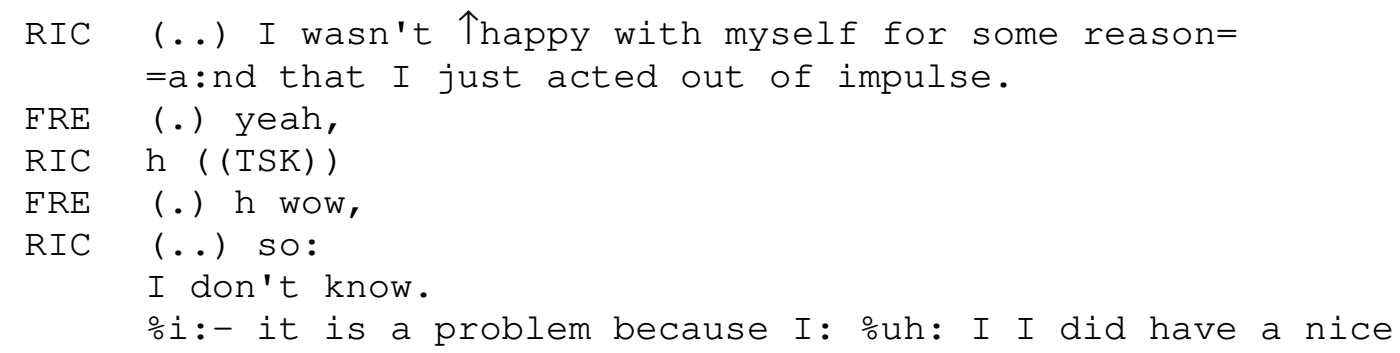




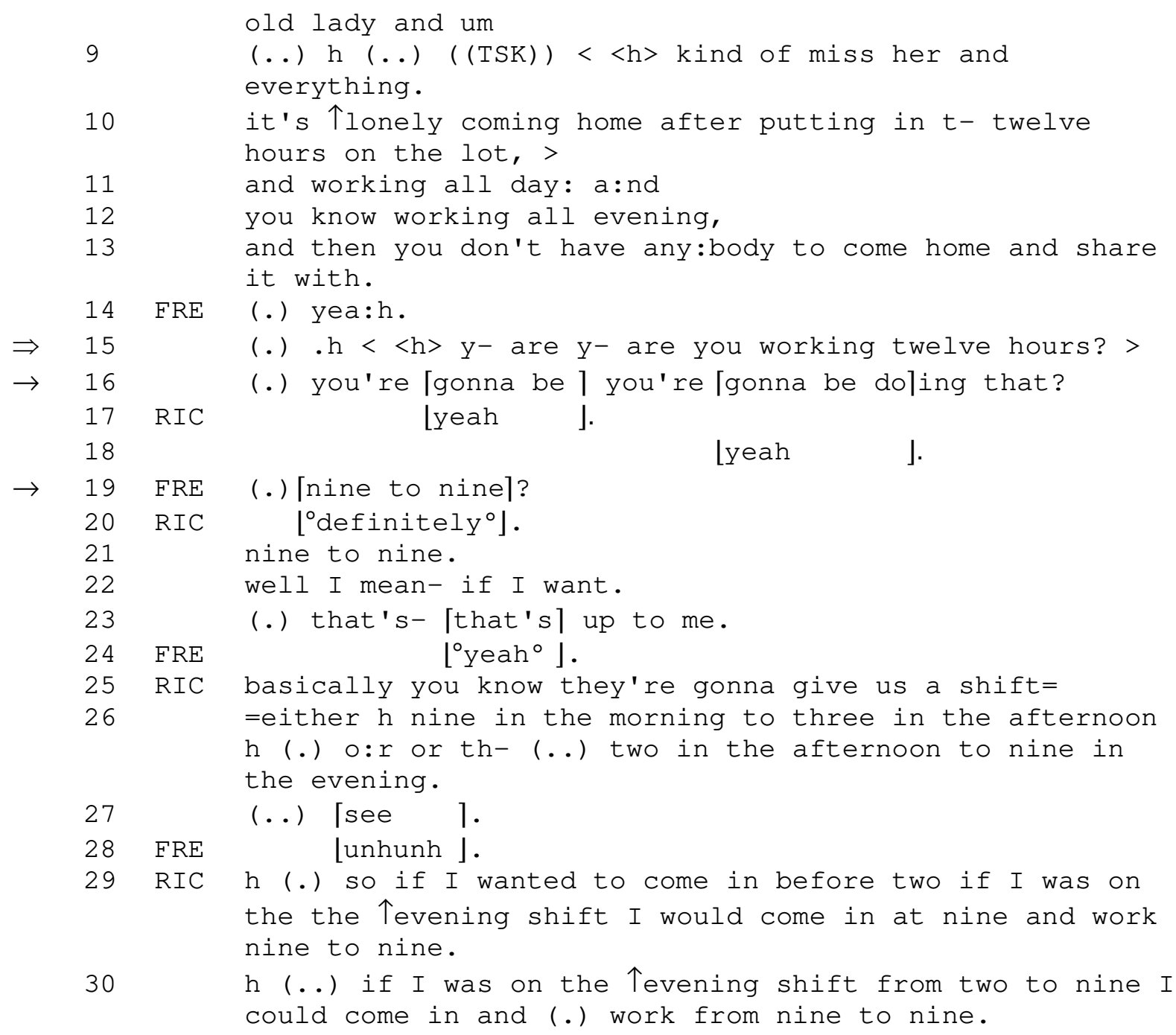

RIC treats FRE's polar question ("are you gonna be working twelve hours?"I.15) as a simple request for information and responds with a slightly delayed type-conforming answer (Raymond, 2003): "yeah" (I.17). FRE asks again the same question twice ("you're gonna be doing that?" I.16, "nine to nine?" I.19). RIC provides his first answer ("yeah" I.17) and a second identical one ("yeah" I.18) in overlap with FRE's second question (I.16). Though in overlap, RIC has twice provided the piece of information requested by FRE by this point in the extract. Yet, FRE's third question ("nine to nine?" I.19) suggests that he is pursuing a more extended response and not treating RIC's type-conforming answers as sufficient. FRE's topic transition is eventually successful, 
as RIC launches into a detailed explanation of how shifts are organized at his new job (I.21-30).

\section{Combination of cues}

On top of the role that register span, discourse markers, and questions can play in topic management, the three different types of cues tend to combine, and the typical topic transition involves two or more. Participants do not solely choose a cue, they design their transitions with meaningful combinations of cues - and this is what truly characterizes topic transitions in interaction.

\subsection{Quantitative results}

This section investigates the phenomenon of multiple marking through the lens of statistical modeling. A first logistic regression ("LogReg1", reported in Table 1) models the effect that the three variables have on topic structure (175 Transitions, 275 Continuities): the use of an expanded register span, a discourse marker, or a question.

Table 1. LogReg1: multivariate logistic regression modeling the association between three different cues and topic transition.

\begin{tabular}{lrll} 
& Odds ratio & {$[$ Confidence Interval 95\%] } & $\boldsymbol{p}$ value \\
\hline Discourse marker & 2.49 & {$[1.63-3.82]$} & $<0.001\left(^{*}\right)$ \\
Question & 4.60 & {$[2.47-8.83]$} & $<0.001\left(^{*}\right)$ \\
Expanded span & 4.02 & {$[2.49-6.57]$} & $<0.001\left(^{*}\right)$ \\
\hline $\mathrm{N}=450$, AIC $=530.81$ & & & \\
n.s. $=$ not significant $(p \geq 0.05) ;{ }^{*}=$ significant $(p<0.05)$ &
\end{tabular}

The three variables tested for are highly significant, as shown by the $p$ values. Expressed as odds ratios, the estimates indicate their effect size and relative importance. The presence of a question is the strongest associated factor, as speakers are 4.60 times more likely to be initiating a topic transition when their TCU 
is a question. The second strongest associated factor is register span, as a TCU is 4.02 times more likely to be a Transition if it is delivered with an expanded register span. The presence of a discourse marker is the least predictive factor, but still shows a strong correlation to topic transition, as speakers are 2.49 times more likely to be doing a Transition when they preface their TCU with a discourse marker. The full statistical report for LogReg1 is presented in Appendix B. In sum, LogReg1 shows that there is a highly significant and strong correlation between the topic status of a TCU (Transition vs. Continuity) and the use of one the following cues: a TCU-initial discourse marker, a question, and expanded register span. The model predicts that the mobilization of any of these three cues is correlated to the interactional action of transitioning to a new topic.

Another crucial aspect of TCU-design involves the combined use of such cues. A critical difference between Transition and Continuity is that speakers routinely mobilize more than one type of cue for their Transitions. Figure 1 illustrates the amount of different types of cues that TCUs mobilize.

Figure 1. Combination of different types of cues.

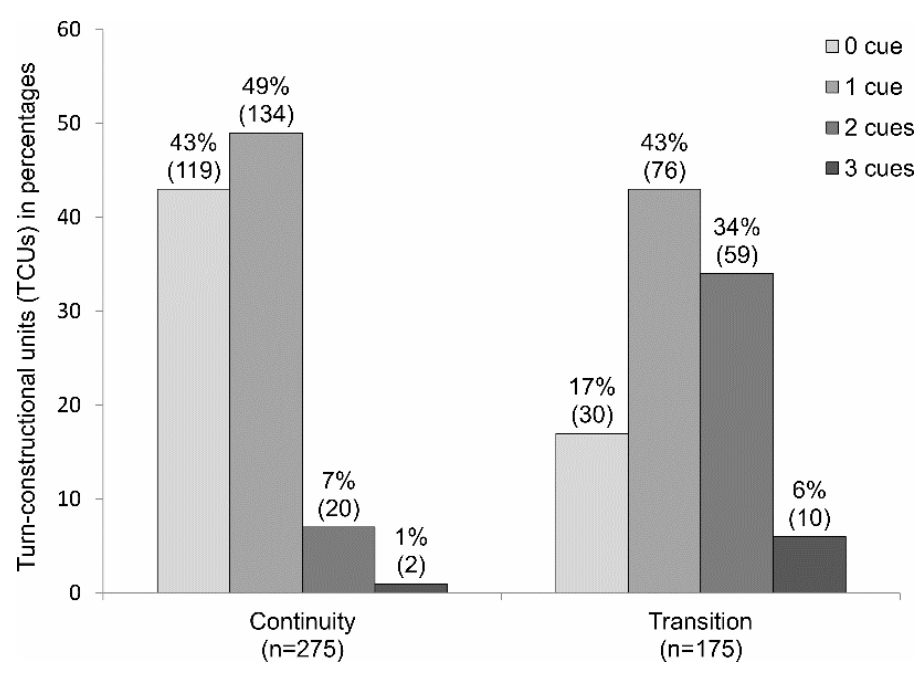

For a TCU to contain only one of the three types of cues is not typical of Transitions, as a comparable proportion of Transitions (43\%) and Continuities (49\%) mobilizes one type of cue only - irrespective of the type of cue. What is more striking is that 
combining two types of cues is much more common for Transitions (34\%) than in the case of Continuity (7\%). Besides, Continuity mobilizes zero cues in a higher proportion (43\%), while only $17 \%$ of Transitions remain unaccounted for when analyzing questions, discourse markers and register span. Mobilizing two or three cues is very rare for Continuity (8\%), but concerns $40 \%$ of Transitions.

A second logistic regression ("LogReg2", Table 2) confirms that topic structure is correlated to the amount of cues that speakers use to design their TCUs.

Table 2. LogReg2: univariate logistic regression modeling the combination of different types of cues and topic transition.

\begin{tabular}{lrlc} 
& Odds ratio & {$[$ Confidence Interval 95\%] } & $p$ value \\
\hline 1 cue & 2.54 & {$[1.56-4.22]$} & $<0.001\left(^{*}\right)$ \\
2 cues & 13.57 & {$[7.08-27.19]$} & $<0.001\left(^{*}\right)$ \\
3 cues & 21.43 & {$[5.29-144.61]$} & $<0.001\left(^{*}\right)$ \\
\hline
\end{tabular}

$N=450, A I C=528.87$

n.s. $=$ not significant $(p \geq 0.05) ;{ }^{*}=$ significant $(p<0.05)$

A considerable proportion of Transitions combines two types of cues, while it is a rare scenario for Continuity: speakers are 13.57 times more likely to be initiating a Transition when they use two different types of cues, e.g., a question and expanded register span. Combining the three different types of cues is rare but strongly associated with Transition: a TCU which does so is 21.43 times more likely to be a Transition. The full statistical report for LogReg2 is presented in Appendix C. These results suggest that topic transition typically mobilizes more than one type of cue.

\subsection{Qualitative analyses}

The extract presented in (5) is an example of a topic transition signaled with the combination of two different cues: expanded span and a discourse marker. MIC and JIM have been talking about superconductors, and the extract starts just before a topic transition about biology research ("but there's one technology that's u:m (.) 
gonna overtake that and that's: D:NA research" I.2). The topic transition of interest here comes later in the extract ("well I hope I hope they use fractals" I.17).

\section{(5) Fractals (SBC017, 295-350)}

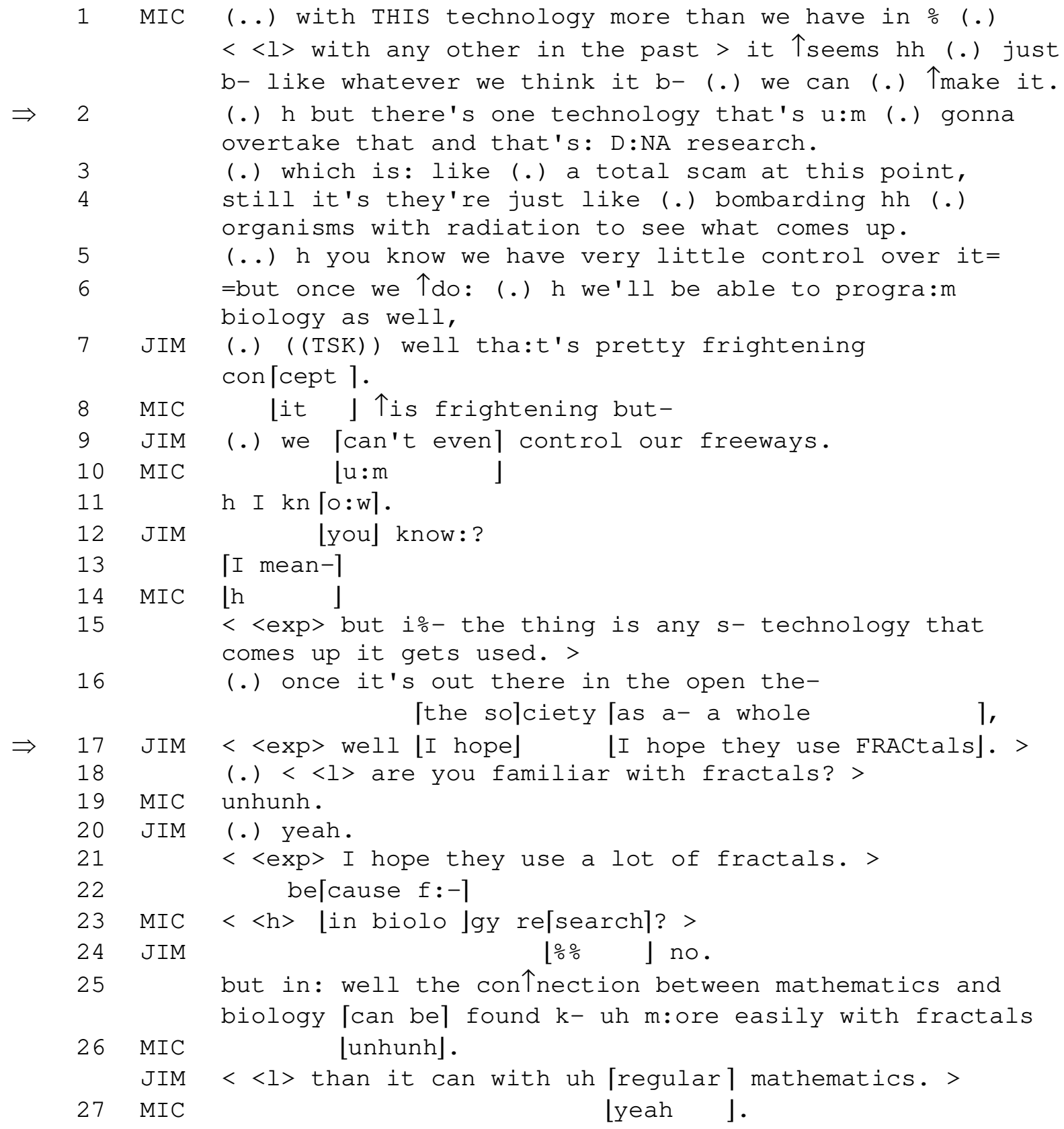

JIM initiates a topic transition about a subject he is very interested in discussing throughout the conversation, namely, fractals ("well I hope they use fractals" I.17). 
The grammatical design of the transition corresponds closely to the findings of the present study, as it involves an expanded register span in combination with the disjunctive discourse marker well. However, JIM's tentative transition I.17 fails to prompt a smooth topic switch despite its canonical design. Traces of a problematic transition can be seen in the fact that I.18, JIM recycles part of his transition from I.17 ("are you familiar with fractals?"). The repeat can be thought necessary because the first instance of the transition I.17 was produced in overlap ${ }^{2}$ with MIC's turn I.16 and may have lost some of its impact. However, JIM rephrases his turn and switches from "I hope" to the more constraining "are you familiar with", making it clearer that his first try was not a simple assessment but a topic transition trying to engage its recipient. MIC's confirmation token ("unhunh" I.19) is fitted to the polar question it answers (Raymond, 2003). However, I expand from Schegloff (2007:169-180) in arguing that the preferred response to a topic question is to provide extended ontopic talk rather than just the answer projected by the logical-semantic format of the question. Further trouble is suggested by MIC's repair initiation ("in biology research?" I.23), which may be heard as a sanction of JIM's transition. JIM seems to be claiming that his transition is closely connected to the previous topic, in part through his use of the pronoun "they" (I.17) which co-refers to a generic group of scientists with an earlier use of "they" (I.4). The stepwise character of the transition (Jefferson, 1984) is challenged by MIC, who forces JIM to render the connection explicit ("no but in: well the connection between mathematics and biology can be found k- uh m:ore easily with fractals" I.24-25). It appears later in the conversation that JIM, who keeps mentioning fractals, does not fully understand what they are. MIC seems to be more knowledgeable about it, but declines several opportunities to

\footnotetext{
${ }^{2}$ Competitive overlap has been showed to be associated with prosodic variations, especially concerning register level (Kurtic et al., 2009, but see Sikveland and Zeitlyn, 2017), and it is possible that JIM's expanded register span is used to compete for the floor at the same time as it signals topic transition.
} 
develop said topic and seems to avoid contradicting and disaligning with JIM on the matter. This example illustrates that a typical combination of cues to topic transition does not guarantee in any way its interactional success. In (5), the transition seems to be identified as problematic by the recipient and is minimally ratified. One could also argue it is precisely in prevision of the potentially problematic nature of the topic switch that JIM designs his transition with two typical cues I.17.

An extreme case of combination of cues is presented in (6). MAR and ALC are two sisters having a late-night conversation during the holiday season. The extract starts when MAR wonders whether they could train the family dog ("she" I.1). After the topic falters, ALC initiates a topic transition (I.13) about a conflict she had with Tim and Mandy, the couple with whom she and her partner share a house.

\section{(6) $\operatorname{Tim}(\mathrm{SBC} 007,309-329)$}

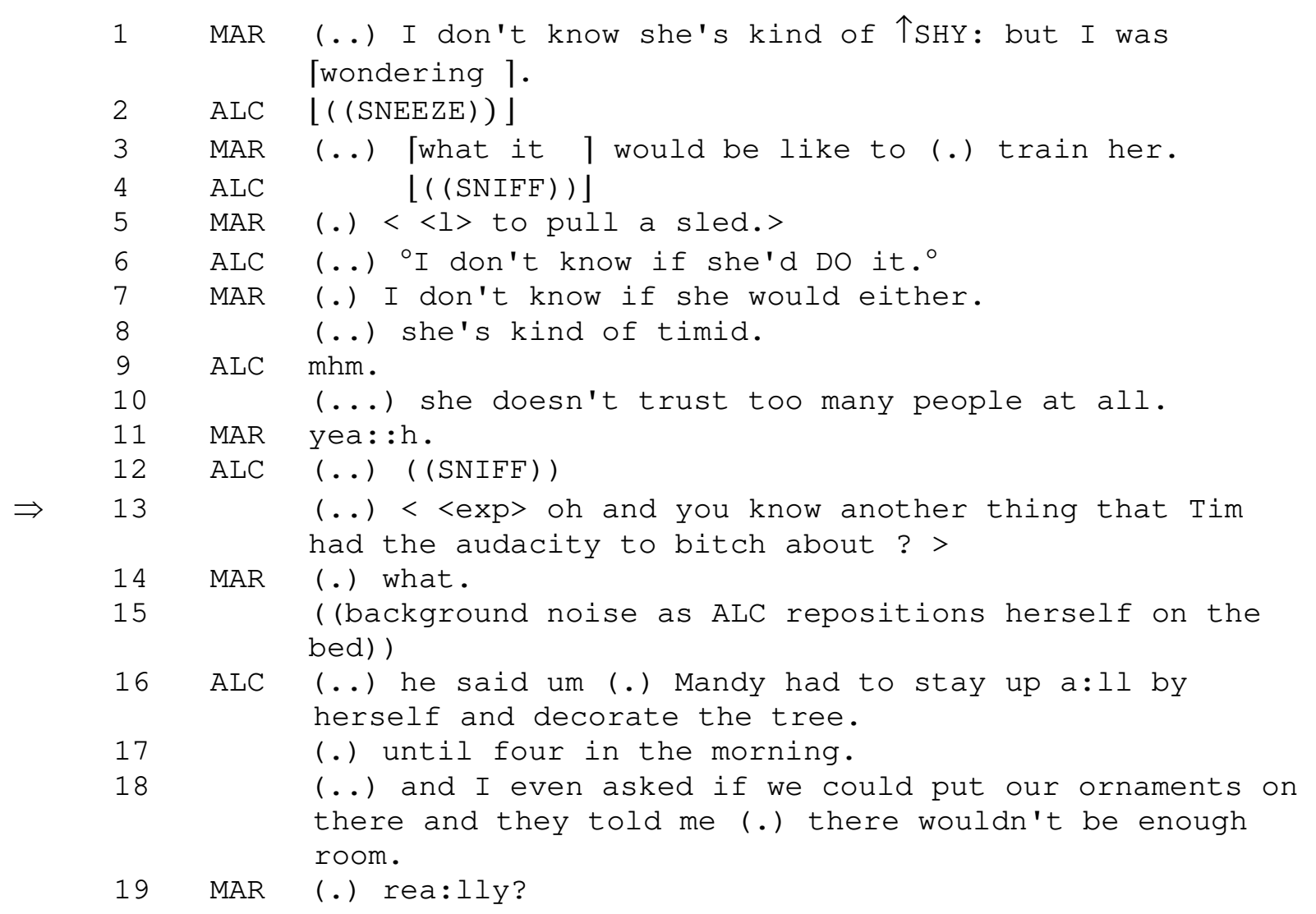


The topic transition in (6) has the appearance of a prototypical topic transition, as it combines expanded register span, a question, and three discourse markers (oh, and, you know). Statistical modeling showed that combining the three types of cues in one TCU is closely associated to topic transition. However, the low frequency of such a pattern (6\% of Transitions) also suggests that this is not a typical practice. What is done more routinely by conversational participants is to combine two types of cues, as in the transition analyzed in Extract (5) and which combined a discourse marker and expanded register span.

Upon first inspection, the topic transition in (7) can be considered a deviant case as far as its linguistic design is concerned, as it does not involve any of the three types of cues analyzed here. PAM has been talking about raising children in a metaphysical light (I.1-6), to which her partner DAR jokingly answers that their children are a very concrete part of their lives (I.7-8). After shared laughter (I.9-10) and further on-topic talk (11-13), PAM initiates a topic transition about a conversation she had with their daughter Natalie about Santa Claus (I.14).

(7) Santa Claus (SBC005, 453-491)

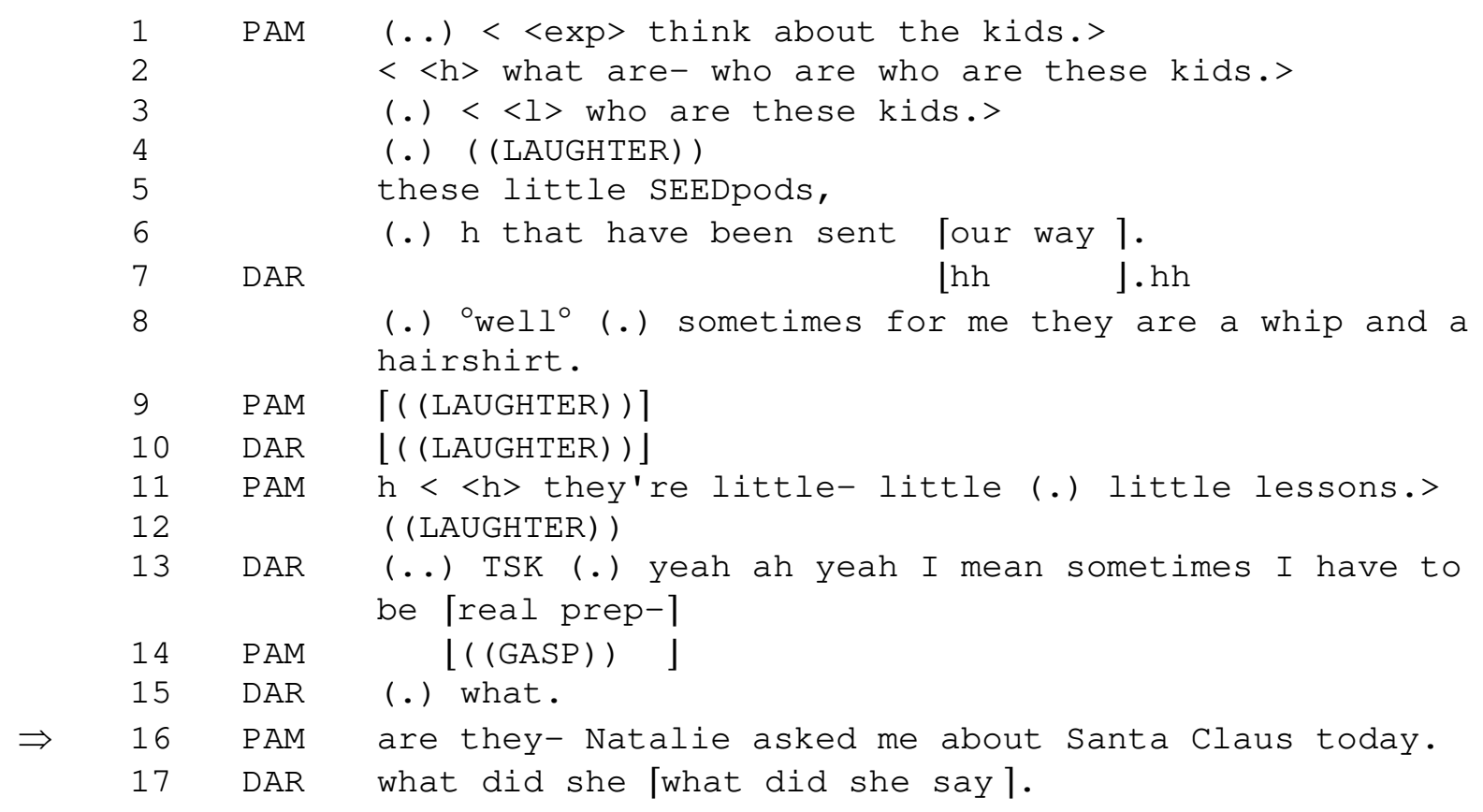




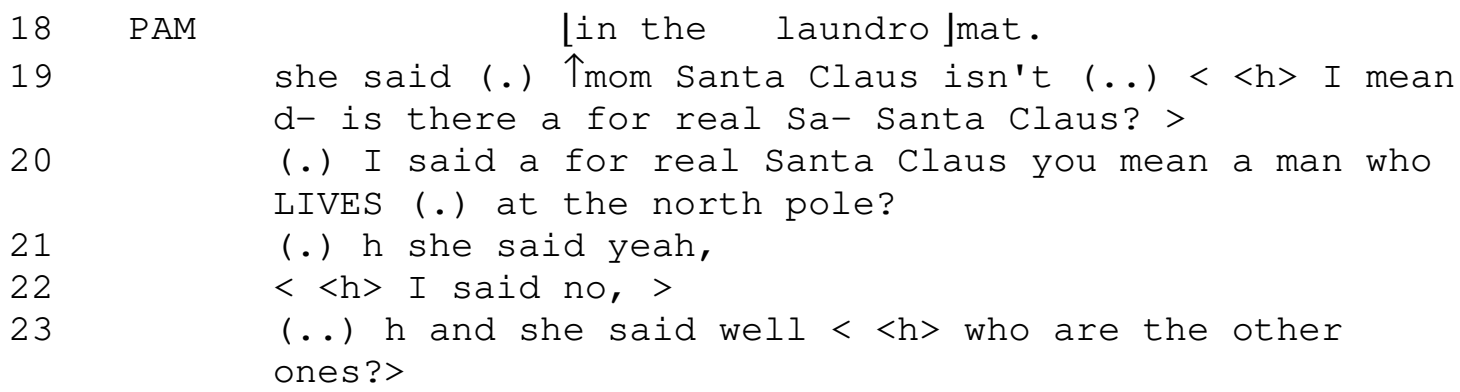

The design of the topic transition itself ("Natalie asked me about Santa Claus today" I.14) does not involve any identifiable cue. However, the change of topics is preceded by a sequence which may be interpreted as a pre-sequence to the topic transition. PAM delivers a loud and exaggerated gasp (I.14), effectively interrupting DAR midturn (I.13). After a micro-pause, DAR's "what" (I.15) is a go-ahead response (Schegloff, 2007:49). By indexing a strong emotion, PAM's gasping can be heard as a form of justification for bypassing turn-taking (interrupting) and topic continuity. Thus, the pre-sequence (I.14-15) already signals disjunction. PAM's next turn (I.16) is then clearly understood as opening a new topic without resorting to a dedicated linguistic design. This extract shows that transitioning to a different topic can be implemented in various ways, as participants may tap into a pool of different strategies. However, more research on the linguistic design of transitions and how it intersects with sequential structure is needed for a better understanding of the topic trajectories of casual conversation.

\section{Conclusion}

This multi-domain and mixed-methods study of spontaneous American English conversations investigated various aspects of the linguistic format that participants can give to their topic transitions. I operated on the grounds of a binary distinction between TCUs that implement a topic Transition as opposed to TCUs doing topic Continuity. Despite this over-simplification, it translated into clear results setting apart topic transition as a distinct interactional action. To the best of my knowledge, 
the present study is the first holistic and mixed-methods analysis of the grammatical design of topic transition. By focusing on spontaneous interaction, it contributes to a better understanding of what it is that participants do when they transition to a new topic, and the linguistic resources they mobilize to do so. I demonstrated that TCUinitial discourse markers, questions, and expanded register span are consistent cues to topic transition, contributing to our understanding of how speakers create a topic architecture and manage topics in a conversation. Logistic regression confirmed that 1) each type of cue plays a crucial role in signaling transitions, and 2) Transition further differs from Continuity in that it routinely mobilizes more than one type of cue. Topic transitions are thus characterized by a series of features setting them apart as a recognizable action, and despite variety of content and placement, providing evidence that transitioning to a new topic is an interactional action implemented through the orchestration of recurring grammatical practices. Starting from the interactional action thus makes it possible to identify the multifaceted repertoire shaping grammar in interaction.

The next step would be to analyze more closely the manner in which different types of cues co-exist and participate in topic transition with their unique contribution. Since a varied set of cues can be mobilized to signal transition, the ways in which they co-exist as concurrent strategies require further analysis. Future studies should determine what the unique contribution of each is, and how they can complement or contradict each other across diverging modalities (verbal, prosodic, and possibly kinetic). Further research is needed on various subtypes of topic transition, such as the difference traditionally made between stepwise and disjunctive transitions (Holt and Drew, 2005; Jefferson, 1984; Maynard, 1980). It remains to be shown to what extent diverging modes of switching topics may bear on the linguistic design of transitions. Future research is also needed to investigate topic transition in an embodied perspective, e.g. focusing on cues such as body sway (Stevanovic et al., 2017) and gaze directions (Kendrick and Holler, 2017). 


\section{Acknowledgements}

I am very grateful to Eric Corre, Elisabeth Delais-Roussarie, and Dylan Glynn for their kind and most helpful comments and suggestions at various stages of the doctoral research from which this paper stems. I am also indebted to the two anonymous reviewers whose observations helped enormously in the preparation of the final draft.

\section{Funding}

This work was supported by the Scientific Council of the Sorbonne-Nouvelle University through a doctoral grant awarded by the Doctoral School of English, German, and European Studies of the Sorbonne-Nouvelle University; additional support was provided by the Department of Linguistics and Doctoral School of Linguistics of Paris Diderot University.

\section{References}

Bates, Douglas, Maechler, Martin, Bolker, Ben \& Walker, Steve, 2014. Ime4: Linear Mixed-Effects Models Using Eigen and S4. R package version 1.1-7. http://CRAN.R-project.org/package=Ime4 (accessed 31.10.16).

Berthoud, Anne-Claude, 1996. Paroles à propos: approche énonciative et interactive du topic. Technip Ophrys Editions, Paris; Gap.

Boersma, Paul, Weenink, David, 2012. Praat, Doing Phonetics by Computer [Computer program]. Version 5.3.23. http://www.praat.org/ (accessed 01.11.13).

Bolden, Galina B., 2006. Little words that matter: discourse markers "so" and "oh" and the doing of other-attentiveness in social interaction. Journal of Communication 56, 661-688. doi:10.1111/j.1460-2466.2006.00314.x 
Bolden, Galina B., 2008. "So what's up?": using the discourse marker so to launch conversational business. Research on Language and Social Interaction 41, 302 337. doi:10.1080/08351810802237909

Bolden, Galina B., 2009. Implementing incipient actions: the discourse marker "so" in English conversation. Journal of Pragmatics 41, 974-998. doi:10.1016/j.pragma.2008.10.004

Button, Graham, Casey, Neil, 1984. Generating topic: The use of topic initial elicitors. In: Atkinson, J.M., Heritage, J. (Eds.), Structures of Social Action: Studies in Conversation Analysis. Cambridge University Press; Editions de la Maison des sciences de l'homme, Cambridge; Paris, pp. 167-190.

Button, Graham, Casey, Neil, 1985. Topic nomination and topic pursuit. Human Studies 8, 3-55.

Chafe, Wallace L., 1994. Discourse, consciousness, and time: The flow and displacement of conscious experience in speaking and writing. University of Chicago Press, Chicago; London.

Clayman, Steven E., 2013. Turn-Constructional Units and the Transition-Relevance Place. In: Sidnell, J., Stivers, T. (Eds.), The Handbook of Conversation Analysis. Wiley-Blackwell, Chichester, pp. 150-166.

Clift, Rebecca, 2016. Conversation Analysis. Cambridge University Press, Cambridge. Couper-Kuhlen, Elizabeth, 2004. Prosody and sequence organization in English conversation. In: Couper-Kuhlen, E., Ford, C.E. (Eds.), Sound Patterns in Interaction. John Benjamins, Amsterdam; Philadelphia, pp. 335-376.

Couper-Kuhlen, Elizabeth, 2012. Some truths and untruths about final intonation in conversational questions. In: De Ruiter, J.P. (Ed.), Questions: Formal, Functional and Interactional Perspectives. Cambridge University Press, New York, pp. 123-145.

Couper-Kuhlen, Elizabeth, Selting, Margret, 1996. Prosody in Conversation: Interactional Studies. Cambridge University Press, Cambridge, New York. 
Degand, Liesbeth, 2014. "So very fast very fast then" Discourse markers at left and right periphery in spoken French. In: Beeching, K., Detges, U. (Eds.), Discourse Functions at the Left and Right Periphery: Crosslinguistic Investigations of Language Use and Language Change. Brill, Leiden, pp. 151-178.

Di Cristo, Albert, Auran, Cyril, Bertrand, Roxane, Chanet, Catherine, Portes, Cristel, Régnier, Alain, 2004. Outils prosodiques et analyse du discours. Cahiers de l'Institut de Linguistique de Louvain 28, 27-84.

Diewald, Gabriele, 2013. "Same same but different" - Modal particles, discourse markers and the art (and purpose) of categorization. In: Degand, L., Cornillie, B., Pietrandrea, P. (Eds.), Discourse Markers and Modal Particles: Categorization and Description. John Benjamins, Amsterdam; Philadelphia, pp. $19-45$.

Du Bois, John W., Chafe, Wallace L., Meyer, Charles, Thompson, Sandra A., Englebretson, Robert, Martey, Nii, 2000-2005. Santa Barbara Corpus of Spoken American English, Parts 1-4. Linguistic Data Consortium, Philadelphia.

Ford, Cecilia E., Fox, Barbara A., Thompson, Sandra A., 1996. Practices in the construction of turns: The "TCU" revisited. Pragmatics 6, 427-54.

Ford, Cecilia E., Fox, Barbara A., Thompson, Sandra A., 2002. Constituency and the grammar of turn increments. In: Ford, C.E., Fox, B.A., Thompson, S.A. (Eds.), The Language of Turn and Sequence. Oxford University Press, Oxford, pp. 1438.

Fox Tree, Jean E., Schrock, Josef C., 1999. Discourse Markers in Spontaneous Speech: Oh What a Difference an Oh Makes. Journal of Memory and Language 40, 280 295. doi:10.1006/jmla.1998.2613

Fraser, Bruce, 1999. What are discourse markers? Journal of Pragmatics 31, 931-952. doi:10.1016/S0378-2166(98)00101-5

Geluykens, Ronald, 1993. Topic introduction in English conversation. Transactions of the Philological Society 91, 181-214. doi:10.1111/j.1467-968X.1993.tb01068.x 
Glynn, Dylan, 2014. Techniques and tools: Corpus methods and statistics for semantics. In: Glynn, D., Robinson, J. (Eds.), Corpus Methods for Semantics: Quantitative Studies in Polysemy and Synonymy. John Benjamins, Amsterdam; Philadelphia, pp. 307-341.

Goutsos, Dionysis, 1997. Modeling discourse topic $\bigotimes$ : sequential relations and strategies in expository text, Advances in discourse processes. Ablex, Norwood, N.J.

Grobet, Anne, 2002. L'identification des topiques dans les dialogues. Duculot, Brussels.

Grosz, Barbara J., Sidner, Candace L., 1986. Attention, intentions, and the structure of discourse. Computational linguistics 12, 175-204.

Gundel, Jeanette K., Hedberg, Nancy, Zacharski, Ron, 1993. Cognitive status and the form of referring expressions in discourse. Language 69, 274-307.

Halliday, Michael A.K., Matthiessen, Christian M.I.M., 2004. An introduction to functional grammar. Cambridge University Press, New York.

Harrell, Frank E. Jr., 2014. rms: Regression Modeling Strategies. R package version 4.2-1. https://cran.r-project.org/web/packages/rms/index.html (accessed 21.10.16).

Hayano, Kaoru, 2013. Question design in conversation. In: Sidnell, J., Stivers, T. (Eds.), The Handbook of Conversation Analysis, Blackwell Handbooks in Linguistics. Wiley-Blackwell, Chichester, pp. 395-414.

Hepburn, Alexa, Bolden, Galina, 2013. The Conversation Analytic Approach to Transcription. In: Sidnell, J., Stivers, T. (Eds.), The Handbook of Conversation Analysis. Wiley-Blackwell, Chichester, pp. 57-76.

Heritage, John, 1984. A change-of-state token and aspects of its sequential placement. In: Atkinson, J.M., Heritage, J. (Eds.), Structures of Social Action: Studies in Conversation Analysis. Cambridge University Press; Editions de la Maison des sciences de l'homme, Cambridge; Paris, pp. 299-345. 
Heritage, John, 2013. Turn-initial position and some of its occupants. Journal of Pragmatics 57, 331-337. doi:10.1016/j.pragma.2013.08.025

Holt, Elizabeth, Drew, Paul, 2005. Figurative pivots: The use of figurative expressions in pivotal topic transitions. Research on Language and Social Interaction 38, 35-61. doi:10.1207/s15327973rlsi3801_2

Horne, Merle, Hansson, Petra, Bruce, Gösta, Frid, Johan, Filipsson, Marcus, 2001. Cue words and the topic structure of spoken discourse: The case of Swedish men "but." Journal of Pragmatics 33, 1061-1081. doi:doi.org/10.1016/S03782166(00)00044-8

Hutchby, Ian, Wooffitt, Robin, 1998. Conversation analysis: principles, practices, and applications. Polity Press, Cambridge.

Jefferson, Gail, 1984. On stepwise transition from talk about a trouble to inappropriately next-positioned matters. In: Atkinson, J.M., Heritage, J. (Eds.), Structures of Social Action: Studies in Conversation Analysis. Cambridge University Press; Editions de la Maison des sciences de l'homme, Cambridge; Paris, pp. 191-222.

Jefferson, Gail, 2004. Glossary of Transcript Symbols with an Introduction. In: Lerner, G.H. (Ed.), Conversation Analysis: Studies from the First Generation. John Benjamins Publishing, Amsterdam; Philadelphia, pp. 13-31.

Jucker, A.H., Smith, Sara W., 1998. And people just you know like "wow": Discourse markers as negotiating strategies. In: Jucker, A.H., Ziv, Y. (Eds.), Discourse Markers: Descriptions and Theory. John Benjamins, Amsterdam; Philadelphia, pp. 171-202.

Jucker, Andreas H., Ziv, Yael (Eds.), 1998. Discourse markers: descriptions and theory, Pragmatics \& beyond. John Benjamins, Amsterdam囚; Philadelphia.

Kendon, Adam, 2004. Gesture: Visible Action as Utterance. Cambridge University Press, Cambridge. 
Kendrick, Kobin H., 2017. Using Conversation Analysis in the Lab. Research on Language and Social Interaction 50, 1-11. doi:10.1080/08351813.2017.1267911 Kendrick, Kobin H., Holler, Judith, 2017. Gaze Direction Signals Response Preference in Conversation. Research on Language and Social Interaction 50, 12-32. doi:10.1080/08351813.2017.1262120

Kendrick, Kobin H., Torreira, Francisco, 2015. The timing and construction of preference: A quantitative study. Discourse Processes 52, 255-289. doi:10.1080/0163853X.2014.955997

Kim, Hye Ri Stephanie, 2013. Retroactive Indexing of Relevance: The Use of Well in Third Position. Research on Language and Social Interaction 46, 125-143. doi:10.1080/08351813.2013.780338

Kim, Hye Ri Stephanie, Kuroshima, Satomi, 2013. Turn beginnings in interaction: An introduction. Journal of Pragmatics 57, 267-273. doi:10.1016/j.pragma.2013.08.026

Kurtic, Emina, Brown, Guy J., Wells, Bill, 2009. Fundamental frequency height as a resource for the management of overlap in talk-in-interaction. In: BarthWeingarten, D., Dehé, N., Wichmann, A. (Eds.), Where Prosody Meets Pragmatics, Studies in Pragmatics. Emerald Group Publishing, Bingley, pp. 183-203.

Lambrecht, Knud, 1994. Information structure and sentence form: topic, focus, and the mental representations of discourse referents. Cambridge University Press, Cambridge; New York; Melbourne.

Local, John, Walker, Gareth, 2004. Abrupt-joins as a resource for the production of multi-unit, multi-action turns. Journal of Pragmatics 36, 1375-1403. doi:10.1016/j.pragma.2004.04.006

Maynard, Douglas W., 1980. Placement of topic changes in conversation. Semiotica 30, 263-290. doi:10.1515/semi.1980.30.3-4.263 
Mondada, Lorenza, 2001. Gestion du topic et organisation de la conversation. Cadernos de estudos lingüísticos 41, 7-35. doi:10.20396/cel.v41i0.8636999

Mondada, Lorenza, 2003. Parler topical et organisation séquentielle: L'apport de l'analyse conversationnelle. Verbum 2, 193-219.

Nakajima, Shin'ya, Allen, James F., 1993. A Study on Prosody and Discourse Structure in Cooperative Dialogues. Phonetica 50, 197-210. doi: 10.1159/000261940

Park, Innhwa, 2010. Marking an impasse: The use of anyway as a sequence-closing device. Journal of Pragmatics 42, 3283-3299. doi:10.1016/j.pragma.2010.06.002

R Development Core Team, 2013. R: A language and environment for statistical computing [Computer program]. R Foundation for Statistical Computing, Vienna, Austria. Version 3.0.2 (2013-09-25). http://www.R-project.org (accessed 17.07.14).

Raymond, Geoffrey, 2003. Grammar and social organization: Yes/no interrogatives and the structure of responding. American Sociological Review 68, 939-967.

Riou, Marine, 2015. A methodology for the identification of topic transitions in interaction. Discours 16. doi:10.4000/discours.8997

Riou, Marine, 2017. The Prosody of Topic Transition in Interaction: Pitch register variations. Language and Speech. doi:10.1177/0023830917696337

Robinson, Jeffrey D., 2007. The role of numbers and statistics within conversation analysis. Communication methods and measures $1,65-75$. doi:10.1080/19312450709336663

Sacks, Harvey, 1992. Lectures on conversation. 2 vols. Edited by Gail Jefferson with introductions by Emanuel A. Schegloff. Oxford: Basil Blackwell.

Sacks, Harvey, Schegloff, Emanuel A., Jefferson, Gail, 1974. A simplest systematics for the organization of Turn-Taking in Conversation. Language 50, 696-735. doi:10.2307/412243 
Schegloff, Emanuel A., 1993. Reflections on quantification in the study of conversation. Research on language and social interaction 26, 99-128. doi:10.1207/s15327973rlsi2601_5

Schegloff, Emanuel A., 2007. Sequence organization in interaction. Cambridge University Press, Cambridge.

Schegloff, Emanuel A., Sacks Harvey, 1973. Opening up closings. Semiotica 7, 289327. http://dx.doi.org/10.1515/semi.1973.8.4.289

Schiffrin, Deborah, 1987. Discourse markers. Cambridge University Press, Cambridge; New York.

Schourup, Lawrence, 1999. Discourse markers. Lingua 107, 227-265. doi:10.1016/S0024-3841(96)90026-1

Selting, Margret, 2000. The construction of units in conversational talk. Language in Society 29, 477-517.

Selting, Margret, Auer, Peter, Barth-Weingarten, Dagmar, Bergmann, Jörg, Bergmann, Pia, Birkner, Karin, Couper-Kuhlen, Elizabeth, Deppermann, Arnulf, Gilles, Peter, Günthner, Susanne, Hartung, Martin, Kern, Friederike, Mertzlufft, Christine, Meyer, Christian, Morek, Miriam, Oberzaucher, Frank, Peters, Jörg, Quasthoff, Uta, Schütte, Wilfried, Stukenbrock, Anja, Uhmann, Susanne, 2011. A system for transcribing talk-in-interaction: GAT 2 translated and adapted for English by Elizabeth Couper-Kuhlen and Dagmar Barth-Weingarten. Gesprächsforschung 12, 1-51.

Sicoli, Mark A., Stivers, Tanya, Enfield, N.J., Levinson, Stephen C., 2015. Marked initial pitch in questions signals marked communicative function. Language and Speech 58, 204-223. doi:10.1177/0023830914529247

Sidnell, Jack, Stivers, Tanya (Eds.), 2013. The Handbook of Conversation Analysis. Wiley Blackwell, Chichester. 
Sikveland, Rein O., Zeitlyn, David, 2017. Using prosodic cues to identify dialogue acts: methodological challenge. Text \& Talk 37, 311-334. doi:10.1515/text-20170007

Speelman, Dirk, 2014. Logistic regression: A confirmatory technique for comparisons in corpus linguistics. In: Glynn, D., Robinson, J. (Eds.), Corpus Methods for Semantics: Quantitative Studies in Polysemy and Synonymy. John Benjamins, Amsterdam; Philadelphia, pp. 487-533.

Stevanovic, Melisa, Himberg, Tommi, Niinisalo, Maija, Kahri, Mikko, Peräkylä, Anssi, Sams, Mikko, Hari, Riitta, 2017. Sequentiality, Mutual Visibility, and Behavioral Matching: Body Sway and Pitch Register During Joint Decision Making. Research on Language and Social Interaction 50, 33-53. doi:10.1080/08351813.2017.1262130

Stivers, Tanya, 2010. An overview of the question-response system in American English conversation. Journal of Pragmatics 42, 2772-2781. doi:10.1016/j.pragma.2010.04.011

Stivers, Tanya, 2015. Coding Social Interaction: A Heretical Approach in Conversation Analysis? Research on Language and Social Interaction 48, 1-19. doi:10.1080/08351813.2015.993837

Stivers, Tanya, Enfield, N.J., 2010. A coding scheme for question-response sequences in conversation. Journal of Pragmatics 42, 2620-2626. doi:10.1016/j.pragma.2010.04.002

Stivers, Tanya, Enfield, N.J., Brown, Penelope, Englert, Christina, Hayashi, Makoto, Heinemann, Trine, Hoymann, Gertie, Rossano, Federico, De Ruiter, Jan Peter, Yoon, Kyung-Eun, Levinson, Stephen C., 2009. Universals and cultural variation in turn-taking in conversation. Proceedings of the National Academy of Sciences 106, 10587-10592. 
Stivers, Tanya, Rossano, Federico, 2010. Mobilizing Response. Research on Language and Social Interaction. 43,3--31. http://dx.doi.org/10.1080/08351810903471258

Stivers, Tanya, Rossano, Federico, 2012. Mobilising response in interaction: a compositional view of questions. In: De Ruiter, J.P. (Ed.), Questions: Formal, Functional and Interactional Perspectives. Cambridge University Press, New York, pp. 58-80.

Streeck, Jürgen, Goodwin, Charles, LeBaron, Curtis (Eds.), 2011. Embodied Interaction: Language and Body in the Material World. Cambridge University Press, Cambridge; New York.

Szczepek Reed, Beatrice, 2011. Analysing conversation: an introduction to prosody. Palgrave Macmillan, Basingstoke; New York.

Tannen, Deborah, 1984. Conversational style: analyzing talk among friends. Ablex, Norwood, NJ.

Thompson, Sandra A., Fox, Barbara A., Couper-Kuhlen, Elizabeth, 2015. Grammar in Everyday Talk. Building Responsive Actions. Cambridge University Press, Cambridge.

Yule, George, 1980. Speakers' topics and major paratones. Lingua 52, 3-47. doi:10.1016/0024-3841(80)90016-9

Zellers, Margaret, 2011. Prosodic Detail and Topic Structure in Discourse. Unpublished PhD dissertation, University of Cambridge.

Zellers, Margaret, 2013. Prosodic variation for topic shift and other functions in local contrasts in conversation. Phonetica 69, 231-253. doi:10.1159/000353445

Zellers, Margaret, Ogden, Richard, 2014. Exploring Interactional Features with Prosodic Patterns. Language and Speech 57, 285-309. doi:10.1177/0023830913504568 


\section{Appendix A. Transcription conventions.}

The transcription conventions used in this paper mostly correspond to the revised system devised by Gail Jefferson for Conversation Analysis (see for example Jefferson, 2004, and Hepburn and Bolden, 2013), but with normalized orthography, following Szczepek Reed (2011) and Thompson et al. (2015) inter alia. Symbols transcribing prosody are inspired by the GAT 2 system (Selting et al., 2011) for the bracket notations $(<>)$, with an additional notation for register span inspired by Di Cristo et al. (2004). Each numbered line in the transcripts corresponds to a turnconstructional unit (TCU).

ALN

$\rightarrow$

$\Rightarrow$

(.)

$(\ldots)$

$(\ldots)$

$=$

:

1 1

I J

$\uparrow$

$\downarrow$

$<\langle 1\rangle>$

$<\langle\mathrm{h}\rangle>$

$<\langle\mathrm{COm}>>$

$<\langle\exp \rangle>$

? speaker identification

target line referred to in the text

target line (topic transition) referred to in the text

very short pause

short/medium pause

longer pause

latching (no silence between two TCUs)

lengthening

overlap with following turn

overlap with previous turn

pitch upstep

pitch downstep

low register level

high register level

compressed register span

expanded register span

unit-final rising contour 


\begin{tabular}{|c|c|}
\hline • & unit-final falling contour \\
\hline , & unit-final contour slightly falling or rising \\
\hline- & unit-final level contour or mid-unit truncated contour \\
\hline${ }^{\circ}$ word ${ }^{\circ}$ & piano, attenuated speech \\
\hline WORD & loud volume \\
\hline$. h, . h h$ & in-breath \\
\hline h, hh & out-breath \\
\hline$((\mathrm{TSK}))$ & alveolar click \\
\hline @ & laugh pulse \\
\hline wo@rd & laughing word \\
\hline$\%$ & glottal stop, creak \\
\hline $\mathrm{w} \%$ ord & glottalized word \\
\hline$(($ LAUGHTER) ) & laughter \\
\hline$((\operatorname{SNIFF})), \quad((\mathrm{YAWN}))$ & double parentheses indicate non-linguistic sound \\
\hline XXX & unintelligible segment \\
\hline
\end{tabular}

\section{Appendix B. Statistical report for LogReg1.}

Table B.1 LogReg1: model diagnostic for the fixed-effect logistic regression.

\begin{tabular}{ll}
\hline c-statistic & 0.725 \\
Nagelkerke's pseudo R & 0.217 \\
\hline
\end{tabular}

The variance inflation factors (VIF) were used to check for multicollinearity, i.e., checking that the predictor variables are not correlated. The VIF scores were not found to be higher than 4 (Table B.2), which would have suggested that two variables were too similar and that one should be discarded, as highly similar variables would artificially improve results. 
Table B.2 LogReg1: variance inflation factors (VIF) of the fixed-effect logistic regression.

\begin{tabular}{lc} 
& VIF \\
\hline Discourse marker & 1.02266 \\
Question & 1.033058 \\
Span & 1.006706 \\
\hline
\end{tabular}

Interactions between predictors were checked by examining two variables at a time in three alternate models (discourse marker and question, discourse marker and span, question and span). Two variables interact when their combined effect is different from simply adding their respective effect. None of the interactions were found to be significant and were thus discarded.

To cross-validate the model - which was trained on the very data it was asked to predict - I used the resampling technique of bootstrapping (Somers Doxy) and set it so that the model could be tested 500 times (Table B.3). After 500 bootstraps, the cstatistic did not change (0.725). The bootstrapped pseudo $R^{2}(0.217)$ was still very close to the original pseudo $R^{2}(0.213)$, which indicates that the model does not suffer from over-dispersion. This can be considered an internal validation of the model.

Table B.3. LogReg1: fixed-effect logistic regression after 500 bootstraps (Somers Doxy).

\begin{tabular}{ll}
\hline c-statistic & 0.721 \\
Nagelkerke's pseudo R² & 0.220 \\
\hline
\end{tabular}

An additional model including Speaker as a random variable is presented in Table B.4. Compared with the earlier model including fixed effects only and which yielded a cstatistic of 0.724 , the mixed-effect model has a c-statistic of 0.758 . Thus, once the model takes into account the effect that different speakers have on the data, the cstatistic rises slightly, translating into a better predictive strength. 
Table B.4. Mixed-effect logistic regression model - cues to topic transition.

\begin{tabular}{|c|c|c|c|c|c|c|}
\hline \multicolumn{4}{|l|}{ Fixed effects } & \multicolumn{3}{|c|}{ Random effect } \\
\hline Predictor & Odds Ratio & [95\% C.I.] & $p$-value & Group & Variance & S.E. \\
\hline Discourse marker & 2.42 & {$[1.57-3-72]$} & $<0.001(*)$ & Speaker & 0.13 & 0.36 \\
\hline Question & 5.69 & {$[2.84-11.37]$} & $\left.<0.001{ }^{*}\right)$ & & & \\
\hline Expanded span & 4.30 & [2.61- - 7.07] & $<0.001(*)$ & & & \\
\hline
\end{tabular}

$N=450 ; \mathrm{AIC}=529.3 ;$ c-statistic $=0.760$

C.I.= Confidence Interval; S.E.= Standard Error

n.s. $=$ not significant $(p \geq 0.05) ;{ }^{*}=$ significant $(p<0.05)$

\section{Appendix C. Statistical report for LogReg2.}

The c-statistic and pseudo $\mathrm{R}^{2}$ are presented in Table C.1. All the VIF scores were below 2 (Table C.2). After 500 bootstraps, the c-statistic and pseudo $\mathrm{R}^{2}$ were not considerably lower (Table C.3). Adding speakers as a random variable translated into a better predictive strength: the c-statistic of the mixed-effects model was slightly higher (Table C.4).

Table C.1. LogReg2: model diagnostic for the fixed-effect logistic regression.

\begin{tabular}{ll}
\hline c-statistic & 0.716 \\
Nagelkerke's pseudo $\mathrm{R}^{2}$ & 0.222 \\
\hline
\end{tabular}

Table C.2. LogReg2: variance inflation factors (VIF) of the fixed-effect logistic regression.

\begin{tabular}{ll} 
& VIF \\
\hline 1 cue & 1.384636 \\
2 cues & 1.354240 \\
3 cues & 1.053148 \\
\hline
\end{tabular}


Table C.3. LogReg2: fixed-effect logistic regression after 500 bootstraps (Somers Doxy).

\begin{tabular}{ll}
\hline c-statistic & 0.716 \\
Nagelkerke's pseudo R & 0.222 \\
\hline
\end{tabular}

Table C.4. Mixed-effect logistic regression model - combination of cues to topic transition.

\begin{tabular}{|c|c|c|c|c|c|c|}
\hline \multicolumn{4}{|c|}{ Fixed effects } & \multicolumn{3}{|c|}{ Random effect } \\
\hline Predictor & Odds Ratio & {$\left[\begin{array}{lll}95 \% & C . / .\end{array}\right]$} & $p$-value & Group & Variance & S.E. \\
\hline 1 cue & 2.55 & {$[1.54-4-21]$} & $<0.001(*)$ & Speaker & 0.09 & 0.29 \\
\hline 2 cues & 14.49 & {$[7.29-28.81]$} & $<0.001(*)$ & & & \\
\hline 3 cues & 24.74 & {$[4.96-123.42]$} & $<0.001(*)$ & & & \\
\hline \multicolumn{7}{|c|}{$N=450 ;$ AIC $=529 ;$ C-statistic $=0.753$} \\
\hline \multicolumn{7}{|c|}{ C.I.= Confidence Interval; S.E.= Standard Error } \\
\hline \multicolumn{7}{|c|}{ n.s. $=$ not significant $(p \geq 0.05) ; *=$ significant $(p<0.05)$} \\
\hline
\end{tabular}

